The University of Southern Mississippi

The Aquila Digital Community

Faculty Publications

$1-1-2009$

\title{
Variation of Morphology and Elemental Concentrations in the California Nickel Hyperaccumulator Streptanthus polygaloides (Brassicaceae)
}

\author{
Robert S. Boyd \\ Auburn University, boydrob@auburn.edu \\ Michael A. Wall \\ San Diego Natural History Museum \\ Scott R. Santos \\ Auburn University \\ Michael A. Davis \\ University of Southern Mississippi, Mike.Davis@usm.edu
}

Follow this and additional works at: https://aquila.usm.edu/fac_pubs

Part of the Plant Sciences Commons

\section{Recommended Citation}

Boyd, R. S., Wall, M. A., Santos, S. R., Davis, M. A. (2009). Variation of Morphology and Elemental Concentrations in the California Nickel Hyperaccumulator Streptanthus polygaloides (Brassicaceae). Northeastern Naturalist, 16(sp5), 21-38.

Available at: https://aquila.usm.edu/fac_pubs/8412

This Article is brought to you for free and open access by The Aquila Digital Community. It has been accepted for inclusion in Faculty Publications by an authorized administrator of The Aquila Digital Community. For more information, please contact Joshua.Cromwell@usm.edu. 


\title{
Variation of Morphology and Elemental Concentrations in the California Nickel Hyperaccumulator Streptanthus polygaloides (Brassicaceae)
}

\author{
Robert S. Boyd ${ }^{1, *}$, Michael A. Wall ${ }^{2}$, Scott R. Santos ${ }^{3}$, \\ and Michael A. Davis ${ }^{4}$
}

\begin{abstract}
The Ni hyperaccumulator Strepthanthus polygaloides (Brassicaceae) is one of a handful of $\mathrm{Ni}$ hyperaccumulators known from continental North America. Surveys have revealed four distinctive morphs of this species, relying primarily on floral traits (sepal color and shape): a purple sepal morph (P), a yellow sepal morph $(\mathrm{Y})$, a morph in which sepals start yellow and mature to purple (Y/P), and a morph with light yellow undulate sepals $(U)$. In this study, we raised plants from ten populations (five $Y$, three $P$, one $Y / P$, and one $U$ ) under uniform greenhouse conditions to determine if morphs varied in morphology and elemental concentrations when grown on $\mathrm{Ni}$-amended potting soil in a common garden. Morphological data included measurements of leaf form (length, width, and degree of lobing) and plant size (height to first flower as they bolted in summer). Phenology was documented by noting flowering timing of plants. Elemental concentrations of plants were also determined for nine elements $(\mathrm{Ca}, \mathrm{Cu}, \mathrm{Fe}, \mathrm{K}$, $\mathrm{Mg}, \mathrm{Mn}, \mathrm{Ni}, \mathrm{P}$, and $\mathrm{Zn}$ ). All morphological/phenological traits measured varied significantly between at least some morphs. The $U$ and $Y / P$ morphs were larger than $\mathrm{Y}$ and $\mathrm{P}$ morphs, with larger leaves as well. Leaves of $\mathrm{U}$ morph plants had wide sinuses and shallow lobes, whereas $\mathrm{Y} / \mathrm{P}$ plants had narrow sinuses and long narrow lobes. P morph plants were shortest in stature, with the smallest leaves. Morphs also varied significantly in concentrations of all elements except Fe. All populations hyperaccumulated $\mathrm{Ni}$, but the $\mathrm{P}$ morph contained significantly greater $\mathrm{Ni}$ levels than the other three morphs. The $\mathrm{P}$ morph also had more $\mathrm{Mg}$, and less $\mathrm{Mn}$ and $\mathrm{P}$, than the other morphs. The $\mathrm{U}$ morph had more $\mathrm{K}$ and $\mathrm{Zn}$, but less $\mathrm{Ca}$, than the other morphs. Principal components analysis revealed all four morphs to be distinctive from one another, and also suggested both morphological $/ \mathrm{phenolog-}$ ical and elemental differences between $\mathrm{Y}$ morph populations along a north-south gradient. We conclude that there is considerable genetic divergence between morphs. If additional information shows that morphs are reproductively isolated, then these morphs may require taxonomic subdivision.
\end{abstract}

\footnotetext{
'Department of Biological Sciences, Auburn University, Auburn, AL 36849-5407, USA. ${ }^{2}$ Entomology Department, San Diego Natural History Museum, PO Box 121390, San Diego, CA 92112-1390, USA. ${ }^{3}$ Department of Biological Sciences and Cell and Molecular Biosciences Program, Auburn University, Auburn, AL 368495407, USA. ${ }^{4}$ Department of Biological Sciences, University of Southern Mississippi, Hattiesburg, MS 39406-5018, USA. "Corresponding author - boydrob@auburn.edu.
} 


\section{Introduction}

Serpentine soils are relatively challenging substrates for plant growth (Brooks 1987). In California, serpentine soils form ecological islands surrounded by areas of less harsh soils (Harrison and Inouye 2002) and the serpentine soils host a number of endemic species (Kruckeberg 1984). The insular nature of these serpentine environments (Harrison et al. 2006) is one factor that has contributed to the species-rich California floristic province, recognized as one of 34 global "biodiversity hotspots" (Mittermeier et al. 2005). The flora of these areas includes representatives of many plant types, including some hyperaccumulator plants.

Hyperaccumulator plants have extraordinarily elevated concentrations of elements in their aboveground portions. Brooks et al. (1977) defined $\mathrm{Ni}$ hyperaccumulation as a plant tissue level of at least $1000 \mu \mathrm{g} \mathrm{Ni} / \mathrm{g}$ (on a dry-mass basis). Most Ni hyperaccumulators grow on serpentine soils and, although there are more than $300 \mathrm{Ni}$ hyperaccumulators known worldwide (Baker et al. 2000), the serpentine soils of California host only two Ni hyperaccumulator species (Kruckeberg and Reeves 1995). These are two members of the Brassicaceae: Thlaspi montanum L. (Alpine Pennycress; sometimes split into several species or subspecies that each hyperaccumulate $\mathrm{Ni}$ ) and Streptanthus polygaloides Gray (Milkwort Jewelflower).

The genus Streptanthus is found only in North America and contains about 40 species (Kruckeberg 1984), a number of which are endemic to serpentine soils. One of these serpentine endemics, which also is endemic to California, is $S$. polygaloides. This species has been recognized as being unique within the genus based upon its flower structure. As evidenced by its specific epithet, Greene (1904) pointed out that the flower structure of the species was unlike that of a crucifer, being reminiscent of flowers of the genus Polygala (Polygalaceae). He suggested separating $S$. polygaloides into a separate monotypic genus (Microsemia). Arthur Kruckeberg, who has studied members of the genus (Kruckeberg 1957, 1958, 1969), stated that $S$. polygaloides was quite different from other species in the genus, and that attempts to hybridize it with other species in the genus had failed (Arthur Kruckeberg, University of Washington, Seattle, pers. comm.). Reeves et al. (1981) pointed out that the hyperaccumulation of $\mathrm{Ni}$ in $S$. polygaloides was another unique trait within Streptanthus, and pointed out that the hyperaccumulation trait supported recognition of Microsemia polygaloides.

Streptanthus polygaloides grows only along the western side of the Sierra Nevada in California (Reeves et al. 1981). It is an unusual hyperaccumulator species in that it is an annual, whereas almost all other species reported to hyperaccumulate metals are perennial (Reeves and Baker 2000). Nickel concentrations of field-grown plants range from 1100 to $16,400 \mu \mathrm{g} / \mathrm{g}$ dry mass in leaves, stems, roots, flowers, and fruits (Reeves et al. 1981).

During field studies of the high-Ni insect Melanotrichus boydi Schwartz and Wall (Heteroptera: Miridae), which is monophagous on S. polygaloides (Wall and Boyd 2006), we have noted considerable variation in 
$S$. polygaloides. One striking and variable feature is the color of the sepals (Kruckeberg 1984), which are large compared to the petals and contribute most to the showy nature of the flowers. On the basis of our field observations (Wall and Boyd 2006), we have divided blooming S. polygaloides populations into four morphs in the field. These are: 1) a yellow sepal morph (Y); 2) a purple (rose) sepal morph (P); 3) a yellow-to-purple sepal morph (Y/P); and 4) a cream/yellow undulate sepal morph (U). These morphs are illustrated in Figure 1 and described in more detail below.

The four morphs differ in their geographic extent, with the $\mathrm{Y}$ and $\mathrm{P}$ morphs most widespread geographically and the Y/P and $U$ morphs occupying very small ranges. The $\mathrm{Y}$ morph is most widespread, ranging from serpentine sites in Butte County in the north to Mariposa County in the south. We have noted the $\mathrm{P}$ morph at higher elevation (more eastern) sites in the northern portion of the range of $S$. polygaloides, from Sierra County to southern Placer County. The two other morphs are (to our knowledge) much more geographically restricted. The $\mathrm{Y} / \mathrm{P}$ morph is unusual in that flower buds are yellow, but as a flower matures the sepals change color to purple (hence our "yellow-to-purple" name for this morph; Fig. 1). The precise relationship between floral maturation and color change has not been studied, but the color change appears to occur during anthesis (Fig. 1). We have found this morph only at one serpentine area at the border of Tuolumne and Mariposa counties. Farther north, in Tuolumne County, and farther south along the same band of serpentine in Mariposa County, we have found the Y morph. Finally, there is a relatively isolated serpentine area (Alexander et al. 2007) in Fresno County at which we have found the $U$ morph. Flowers of these

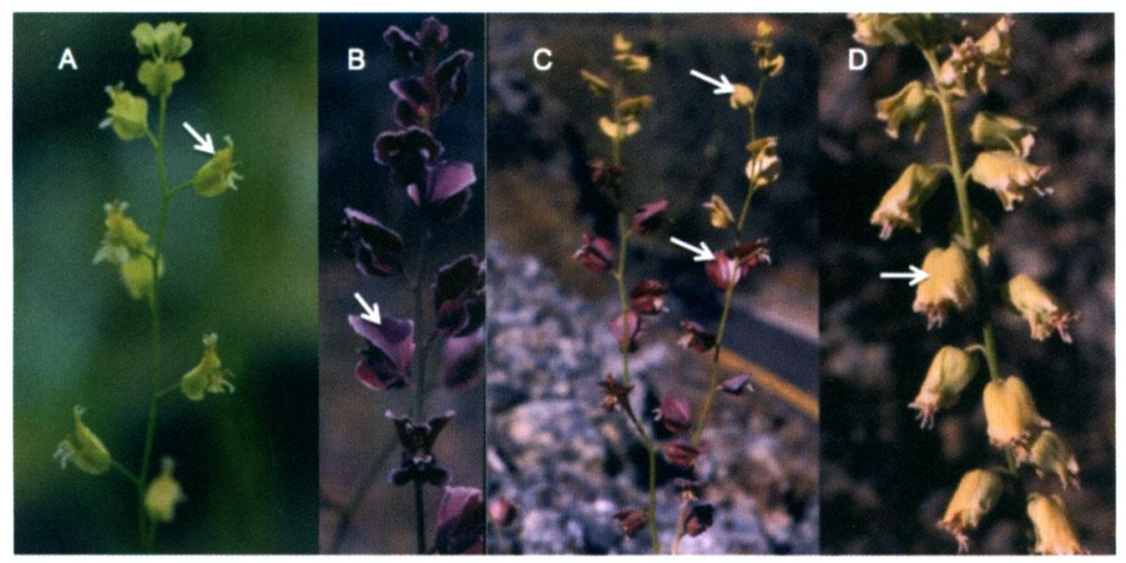

Figure 1. Photographs of the four morphs of $S$. polygaloides, as noted in a prior field study (Wall and Boyd 2006), and investigated in our common garden experiment. Arrows in each photo indicate the sepals of the flowers. A: yellow $(\mathrm{Y})$ morph, B: purple (P) morph, C: yellow-to-purple (Y/P) morph (note that arrows point out both immature yellow and mature purple sepals), and D: undulate (U) morph. Photographs are not to the same scale, but illustrate the sepal color and shape of the morphs investigated in this study. 
plants are light yellow (tending to cream) and the sepals are more undulate, giving the flowers a "frilly" appearance (Fig. 1).

The variation observed in $S$. polygaloides in the field may be due to genotypic or environmental factors. Common garden experiments are one method used to differentiate between these sources of variation in plant traits (Linhart and Grant 1996). In this paper, we report results of a common garden experiment designed to determine if these $S$. polygaloides morphs vary in morphological characteristics and element concentrations (including Ni hyperaccumulation ability) when grown in a uniform environment. This study provides an initial test of the hypothesis that there are genetic differences between the four morphs.

\section{Methods}

We collected seeds from 10 populations of $S$. polygaloides during the summer of 2001. Populations sampled (Table 1) included five Y populations and three $P$ populations. Because their currently known geographic range is restricted, only one population each of the Y/P and U morphs was included in the experiment. Individuals with ripe fruits growing at least $1 \mathrm{~m}$ apart were collected and individually bagged, so that all seeds within a bag were half-sib families. Seeds from at least 19 individuals were collected from each population.

The common garden experiment was conducted in the spring and summer of 2002. High-Ni soil was made by amending Pro-Mix (Premier Horticulture, Red Hill, PA, USA) with powdered $\mathrm{NiCl}_{2}$ (Sigma, St. Louis, MO, USA) to about $800 \mathrm{ppm} \mathrm{Ni}$ (on a dry weight basis). This concentration was achieved by adding $3.2 \mathrm{~g}$ of dried powdered $\mathrm{NiCl}_{2}$ per $14 \mathrm{~L}$ of potting soil. For comparison, Kruckeberg and Reeves (1995) reported that Ni levels of

Table 1. Streptanthus polygaloides populations represented in the greenhouse common garden experiment. Population name abbreviations used in Figure $2 b, d$, and $f$ are provided in parentheses following each population name.

\begin{tabular}{lllc} 
Population name & County & Latitude/Longitude & Elevation (m) \\
\hline Yellow (Y) morph & & & \\
$\quad$ Concow (C) & Butte & $39^{\circ} 47^{\prime} 54.01^{\prime \prime} \mathrm{N} / 121^{\circ} 29^{\prime} 15.61^{\prime \prime} \mathrm{W}$ & 835 \\
Grass Valley (GV) & Nevada & $39^{\circ} 13^{\prime} 28.33^{\prime \prime} \mathrm{N} / 121^{\circ} 03^{\prime} 02.56^{\prime \prime} \mathrm{W}$ & 790 \\
Marshall Road (MR) & El Dorado & $38^{\circ} 50^{\prime} 31.68^{\prime \prime} \mathrm{N} / 120^{\circ} 52^{\prime} 40.76^{\prime \prime} \mathrm{W}$ & 550 \\
Red Hills (RH) & Tuolumne & $37^{\circ} 50^{\prime} 27.00^{\prime \prime} \mathrm{N} / 120^{\circ} 28^{\prime} 08.53^{\prime \prime} \mathrm{W}$ & 370 \\
Bagby (B) & Mariposa & $37^{\circ} 36^{\prime} 48.71^{\prime \prime} \mathrm{N} / 120^{\circ} 08^{\prime} 22.08^{\prime \prime} \mathrm{W}$ & 300 \\
Purple (P) morph & & & 820 \\
$\quad$ Goodyear's Bar (GB) & Sierra & $39^{\circ} 32^{\prime} 26.41^{\prime \prime} \mathrm{N} / 120^{\circ} 52^{\prime} 58.42^{\prime \prime} \mathrm{W}$ & 820 \\
$\quad$ Washington Road (WR) & Nevada & $39^{\circ} 21^{\prime} 34.32^{\prime \prime} \mathrm{N} / 120^{\circ} 48^{\prime} 30.21^{\prime \prime} \mathrm{W}$ & 810 \\
Sugar Pine (SP) & Placer & $39^{\circ} 07^{\prime} 36.18^{\prime \prime} \mathrm{N} / 120^{\circ} 47^{\prime} 07.46^{\prime \prime} \mathrm{W}$ & 1100 \\
Yellow-to-purple (Y/P) morph & & \\
$\quad$ & & & 680 \\
County Line (CL) & Tuolumne & $37^{\circ} 45^{\prime} 15.08^{\prime \prime} \mathrm{N} / 120^{\circ} 15^{\prime} 04.92^{\prime \prime} \mathrm{W}$ & \\
Undulate (U) morph & & & 330 \\
$\quad$ Trimmier (T) & & $36^{\circ} 52^{\prime} 42.40^{\prime \prime} \mathrm{N} / 119^{\circ} 17^{\prime} 25.67^{\prime \prime} \mathrm{W}$ & \\
\hline
\end{tabular}


the serpentine soils they sampled from California Streptanthus sites (including several species besides $S$. polygaloides) ranged from 1060 to $4620 \mathrm{ppm}$, using a strong acid $\left(\mathrm{HF} / \mathrm{HNO}_{3}\right)$ extraction technique.

Soil was placed into $10-\mathrm{cm}$ square pots and topped with a layer of perlite. Pots were divided into rows (blocks) of ten, and a vial of seeds from each population was selected for sowing into that block. Seed vials to be sowed into that block, one from each population, were placed into a bag and drawn arbitrarily from it as we sowed seeds into pots from the front to the back of that row. Thus, the position of the representative of each population varied between rows across the array of pots. The number of seeds sowed in each pot varied depending on seed availability for each half sib, but generally ranged from 25-100 seeds/pot. Plants were grown under ambient light conditions (beginning on 28 February 2002 and ending in mid-July 2002) at a greenhouse complex at Auburn University in Lee County, AL. Pots were watered twice daily and fertilized with an NPK fertilizer once in mid-April. We thinned pots between 40 and 45 days after plants were sown, cutting the smaller plants from each pot to leave 4-7 plants growing in each.

We collected both phenological and morphological information from this experiment. Phenology was documented by noting flowering timing of plants. The date that the first open flower was produced was recorded for each pot. Some plants had not bloomed at the time the experiment was terminated, in mid-July. Pots of these plants were given the termination date as their flowering date. Flowering time was calculated as time in days since seeds were sown at the start of the experiment. We also measured plant size by measuring the height from the soil surface to the first flower of the tallest flowering plant in each pot.

Early in our experiment, we noted substantial variation in leaf form between populations. To our knowledge, this feature has not received study in prior work on this species (Greene 1904, Reeves et al. 1981). Therefore, we collected morphometric data that reflected leaf form (length, width, and metrics reflecting the depth and width of leaf lobes). Specifically, leaf form variables were measured on the two largest plants in each pot 35 days after seeds were sown (in two cases, only one plant was present and so only one measurement was taken). Leaves of $S$. polygaloides are lobed but vary in lobe size; in some cases, leaves are deeply divided. On each of the two largest plants in each pot, the longest leaf was selected and the following data were collected: leaf length (total length from leaf base to tip), leaf width (the largest distance from lobe tip to lobe tip), and sinus width (the distance from the bottom of one sinus to the bottom of another, across the midrib of the leaf, taken at the middle of the leaf). We also collected data reflecting the shape of leaf lobes, which ranged from very narrow and elongate to more broad. We measured lobe width at the leaf middle (the width of a lobe halfway from the sinus to the lobe tip) and lobe width at the lobe base (at the sinus of the leaf). Although we did not directly measure lobe length, we calculated that from our other measurements, as lobe length is equal to leaf 
width minus sinus width, divided by 2 . We also calculated several relative measures of leaf morphology that essentially attempt to factor out differences due to plant size in order to extract shape relationships. These were lobe length/leaf width ratio (which relativized lobe size to the width of a leaf), lobe length/lobe width ratio (which relativized lobe length to width and thus reflected lobe shape), and relative sinus width (\%), which was calculated as sinus width divided by leaf width times $100 \%$. This latter measure relativized sinus width to leaf width. For all leaf variables, data from the two plants in each pot were averaged to generate a single value to represent that pot in the dataset. Single plants were present in just two of the 240 pots that produced plants during the experiment. Sample sizes were: 124 for the yellow morph (25 from Concow, 26 from Grass Valley, 24 from Marshall Road, 24 from Red Hills, and 25 from Bagby), 74 for the purple morph (24 from Goodyear's Bar, 25 from Sugar Pine, and 25 from Washington Road), 25 for the undulate morph (Trimmer), and 17 for the yellow-to-purple morph (County Line).

We also collected the aboveground parts of several plants from most pots (excepting pots with too few plants) for elemental analysis. Tests of plants from all populations with filter paper impregnated with dimethylglyoxime, which generates a semi-quantitative measure of $\mathrm{Ni}$ concentrations (Reeves 1992), showed that all plants hyperaccumulated $\mathrm{Ni}$, but we suspected that the degree of hyperaccumulation might vary between populations. We thinned pots between 40 and 45 days after plants were sown, cutting the smaller plants from each pot to leave 4-7 plants growing in each. Pots with five or fewer plants were not harvested (these were $17 \%$ of the total number of pots that produced plants in the experiment). Sample sizes were: 117 for the yellow morph (26 from Concow, 23 from Grass Valley, 25 from Marshall Road, 22 from Red Hills, and 21 from Bagby), 56 for the purple morph (18 from Goodyear's Bar, 23 from Sugar Pine, and 15 from Washington Road), 26 for the undulate morph (Trimmer), and 14 for the yellow-to-purple morph (County Line). Thinnings were placed into paper sacks and dried at $60{ }^{\circ} \mathrm{C}$ for several days.

\section{Element analysis}

Samples (thinnings) were finely ground, dry-ashed at $485^{\circ} \mathrm{C}$, additionally oxidized in $1 \mathrm{M} \mathrm{HNO}_{3}$, and the residues dissolved in $1 \mathrm{M} \mathrm{HCl}$. We analyzed concentrations of nine elements: the macronutrients $\mathrm{Ca}, \mathrm{K}$, and $\mathrm{P}$, as well as the heavy metals $\mathrm{Cu}, \mathrm{Fe}, \mathrm{Mg}, \mathrm{Mn}, \mathrm{Ni}$, and $\mathrm{Zn}$. An inductively coupled argon plasma spectrometer (Jarrell-Ash, ICAP 9000) was used to determine concentrations of all elements except Ni. Nickel concentrations were determined using an atomic absorption spectrophotometer (Instrumentation Laboratory, IL 251).

\section{Statistical analysis}

Our main objective was to determine if plants of the various morphs and/ or populations differed significantly from each other in this common garden 
setting. We first used one-way analysis of variance (ANOVA) to test whether each variable differed significantly among the morphs. If a significant influence of morph was found for a variable, we used Fisher's protected least significant difference (PLSD) test to determine which morphs significantly differed from others for that variable. Additionally, principal components analysis (PCA) was used to: 1) determine which variable(s) best explained variance between morphs and/or populations, and 2) visualize relationships among morphs and/or populations. The PCAs were done on a combined dataset of 205 samples (pots) for which we had complete information on both morphological/phenological data and elemental concentrations from plants from the same pot. Sample sizes were: 111 for the yellow morph (25 from Concow, 23 from Grass Valley, 22 from Marshall Road, 22 from Red Hills, and 19 from Bagby), 55 for the purple morph (17 from Goodyear's Bar, 23 from Sugar Pine, and 15 from Washington Road), 25 for the undulate morph (Trimmer), and 14 for the yellow-to-purple morph (County Line). For the PCAs, quantitative variables (morphological variation $(M V)$, elemental concentration $(E C)$ and a combined $(M V+E C)$ dataset) were assessed by qualitative categories (floral traits $[F T]$ or populations $[P O P]$ ), along with the $95 \%$ confidence levels of categorical placements. These analyses were conducted with the package FactoMineR v1.10 (Lê et al. 2008) in the R v2.8.1 statistical software environment (R Development Core Team 2008).

\section{Results}

\section{Morphological/phenological data}

Morphs significantly varied in all measured traits (ANOVA, $P<0.05$ ). Post-hoc means separations of plant height data (Table 2) showed that plants of $U$ and $Y / P$ morphs were taller than $Y$ morph plants, and that $P$ morph plants were the smallest of all morphs. A similar size pattern was also found for leaf length, with $U$ and Y/P plants having the longest leaves, $Y$ plants with shorter leaves, and $P$ morph plants with the shortest leaves (Table 2). The pattern for leaf width was slightly different, with Y/P morph plants having the widest leaves, leaves of $U$ and $Y$ morph plants being intermediate in width, and $\mathrm{P}$ morph plants with the narrowest leaves. Scaling leaf length to width, by using a length/width ratio and thus relativizing them, revealed high values for all but the $P$ morph plants (Table 2), the leaves of which were shown to be more rounded in outline by this measure.

Features of leaves that reflected the degree of blade dissection also varied significantly between morphs (Table 2). Leaves of the $U$ morph were least dissected, as revealed by several measurements. The width of the blade from the sinus on one side of the blade to the sinus on the other side (sinus width) was greatest for $\mathrm{U}$ morph plants, intermediate for the $\mathrm{P}$ morph, and least for $\mathrm{Y}$ and $\mathrm{Y} / \mathrm{P}$ plants. Lobe width was also greater in $\mathrm{U}$ plants and least in Y/P plants, although the pattern was slightly different for $\mathrm{P}$ and $\mathrm{Y}$ plants depending on where lobe width was measured (Table 2). For lobe width measured at the middle of a leaf (lobe width middle; Table 2), $\mathrm{P}$ plants 
were equally wide as $U$ plants, with $Y$ plants intermediate between those morphs and Y/P plants. For lobe width measured at the bottom of the lobe (lobe width bottom; Table 2), there was a clear hierarchy of widths, with $\mathrm{U}$ plants the widest, followed in order by $\mathrm{P}, \mathrm{Y}$, and $\mathrm{Y} / \mathrm{P}$ plants. Lobe length also reflected the more dissected nature of $\mathrm{Y} / \mathrm{P}$ morph leaves, which had the longest lobes, followed in order by Y, P, and U plants (Table 2). Scaling lobe length to leaf width and lobe width showed a similar ranking of morphs. Lobe length/leaf width ratios, which reflect the relative length the lobe (and thus are large values for deeply dissected leaves), were greatest for $\mathrm{Y} / \mathrm{P}$ and $Y$ plants, intermediate for $P$ plants, and least for $U$ plants. Lobe length/lobe width middle ratios, which reflect the shape of the lobes (broad or narrow), showed Y/P plants with the greatest values (having long, narrow lobes), $\mathrm{Y}$ plants with wider lobes, and $\mathrm{P}$ and $\mathrm{U}$ plants with relatively broad lobes. Relative sinus width (\%), which scaled sinus width to leaf width, showed the same order of morphs as sinus width when width was measured directly in millimeters (Table 2). The U morph had the largest sinus width (44\%), the $\mathrm{P}$ morph an intermediate value $(31 \%)$, and equally narrow sinus widths $(<15 \%)$ were found for both Y and Y/P morphs.

\section{Elemental analysis}

Elemental concentrations varied significantly among morphs for all elements except Fe (Table 3). The $\mathrm{P}$ morph had significantly different concentrations of four of the nine elements when compared to the other

Table 2. Morphological traits and flowering time (means with SE in parentheses) of $S$. polygaloides morphs documented in the greenhouse common garden experiment. All traits differed significantly among morphs (ANOVA, $P<0.05$ ). Lettered superscripts indicate significant differences between morph means (Fisher's PLSD test, $P<0.05$ ). Sample sizes were: 124 for the yellow morph, 74 for the purple morph, 25 for the undulate morph and 17 for the yellowto-purple morph.

\begin{tabular}{lcccc} 
& \multicolumn{4}{c}{ Morph } \\
\cline { 2 - 5 } Trait measured & Yellow-to-purple \\
\cline { 2 - 5 } & Purple (P) & Yellow (Y) & $(Y / P)$ & Undulate (U) \\
\hline Plant size/phenology & & & & \\
Height to first flower (cm) & $19^{\mathrm{C}}(0.62)$ & $29^{\mathrm{B}}(0.65)$ & $48^{\mathrm{A}}(2.5)$ & $47^{\mathrm{A}}(1.3)$ \\
Time to first open flower (days) & $90^{\mathrm{B}}(1.3)$ & $92^{\mathrm{B}}(1.3)$ & $102^{\mathrm{A}}(1.6)$ & $99^{\mathrm{A}}(1.1)$ \\
Leaf size/form & & & & \\
Leaf length (mm) & $35^{\mathrm{C}}(0.84)$ & $46^{\mathrm{B}}(0.94)$ & $55^{\mathrm{A}}(2.3)$ & $51^{\mathrm{A}}(1.8)$ \\
Leaf width (mm) & $9.3^{\mathrm{C}}(0.16)$ & $10^{\mathrm{B}}(0.24)$ & $12^{\mathrm{A}}(0.69)$ & $10^{\mathrm{B}}(0.33)$ \\
Sinus width (mm) & $2.8^{\mathrm{B}}(0.13)$ & $1.3^{\mathrm{C}}(0.065)$ & $0.96^{\mathrm{C}}(0.025)$ & $4.5^{\mathrm{A}}(0.33)$ \\
Lobe width middle (mm) & $2.6^{\mathrm{A}}(0.078)$ & $1.4^{\mathrm{B}}(0.047)$ & $0.85^{\mathrm{C}}(0.035)$ & $2.4^{\mathrm{A}}(0.13)$ \\
Lobe width bottom (mm) & $3.1^{\mathrm{B}}(0.12)$ & $1.4^{\mathrm{C}}(0.062)$ & $0.90^{\mathrm{D}}(0.041)$ & $3.5^{\mathrm{A}}(0.22)$ \\
Lobe length (mm) & $3.2^{\mathrm{C}}(0.083)$ & $4.5^{\mathrm{B}}(0.13)$ & $5.5^{\mathrm{A}}(0.35)$ & $3.0^{\mathrm{C}}(0.21)$ \\
Leaf size/form ratios & & & & \\
Leaf length/leaf width & $3.9^{\mathrm{B}}(0.12)$ & $4.6^{\mathrm{A}}(0.088)$ & $4.9^{\mathrm{A}}(0.30)$ & $5.0^{\mathrm{A}}(0.21)$ \\
Lobe length/leaf width & $0.69^{\mathrm{B}}(0.013)$ & $0.86^{\mathrm{A}}(0.012)$ & $0.92^{\mathrm{A}}(0.007)$ & $0.57^{\mathrm{C}}(0.032)$ \\
Lobe length/lobe width middle & $1.3^{\mathrm{C}}(0.045)$ & $3.5^{\mathrm{B}}(0.15)$ & $6.8^{\mathrm{A}}(0.61)$ & $1.3^{\mathrm{C}}(0.11)$ \\
Relative sinus width & $31^{\mathrm{B}}(1.3)$ & $14^{\mathrm{C}}(1.2)$ & $8.5^{\mathrm{C}}(0.69)$ & $44^{\mathrm{A}}(3.2)$ \\
(\% of leaf width) & & & & \\
\hline
\end{tabular}


three morphs. Nickel values were greatest for $P$ plants and less for the other morphs. Highest values of $\mathrm{Mg}$ were also found for the $\mathrm{P}$ morph, with intermediate levels in $\mathrm{Y}$ plants and lowest values in $\mathrm{Y} / \mathrm{P}$ and $\mathrm{U}$ plants. Plants of the $\mathrm{P}$ morph also had the least concentrations of $\mathrm{P}$ (phosphorus) and Mn compared to the other morphs.

Several other differences between morphs were also revealed (Table 3). The U morph had significantly higher or lower concentrations than all other morphs for three of the nine elements examined. The $U$ morph had significantly greater levels of $\mathrm{Zn}$ than all other morphs. This morph also had the most $\mathrm{K}$, with $\mathrm{P}$ and $\mathrm{Y}$ morphs intermediate, and the $\mathrm{Y} / \mathrm{P}$ morph having the least. Calcium levels were highest in $\mathrm{P}$ and $\mathrm{Y}$ morphs, intermediate in the $\mathrm{Y} / \mathrm{P}$ morph, and least in the $\mathrm{U}$ morph. The $\mathrm{Y} / \mathrm{P}$ morph was significantly higher or lower than all other morphs for only one element (K), for which it had the least concentration (Table 3). The Y morph had no elements for which it had greater or lesser concentrations than all other morphs. A difference among morphs in $\mathrm{Cu}$ concentration was also documented, although the morphs did not separate clearly from one another in the post-hoc test (Table 3).

\section{Principal components analysis (PCA)}

Consistent with the ANOVAs, all morphs were significantly distinguishable by morphological variation or elemental concentration in one or both dimensions of the PCA (Figs. 2a-d). For morphological/phenological traits, the first and second dimensions explained $46.8 \%$ and $17.5 \%$, respectively, of variability among the morphs (Fig. 2a). In this case, the variable which best described the first dimension was relative sinus width, while that of the second dimension was leaf length, both of which were significantly different

Table 3. Elemental concentrations (dry mass basis, means with SE in parentheses) of plants of the four $S$. polygaloides morphs grown in the greenhouse common garden experiment. Superscripts denote elements for which ANOVA revealed significant differences among morphs $(P<$ 0.05): means for morphs with different superscripts are significantly different (Fisher's PLSD test, $P<0.05$ ). Sample sizes were: 117 for the yellow morph, 56 for the purple morph, 26 for the undulate morph, and 14 for the yellow-to-purple morph.

\begin{tabular}{lcccc} 
& \multicolumn{5}{c}{ Morph } \\
\cline { 2 - 5 } Element & Purple (P) & Yellow (Y) & $\begin{array}{c}\text { Yellow-to-purple } \\
(\mathrm{Y} / \mathrm{P})\end{array}$ & Undulate $(\mathrm{U})$ \\
\hline Macronutrients & & & & \\
$\mathrm{Ca}(\%)$ & $3.08^{\mathrm{A}}(0.054)$ & $3.16^{\mathrm{A}}(0.044)$ & $2.65^{\mathrm{B}}(0.099)$ & $2.11^{\mathrm{C}}(0.061)$ \\
$\mathrm{K}(\%)$ & $2.26^{\mathrm{B}}(0.15)$ & $2.08^{\mathrm{B}}(0.13)$ & $1.38^{\mathrm{C}}(0.21)$ & $3.59^{\mathrm{A}}(0.072)$ \\
$\mathrm{P}(\%)$ & $0.515^{\mathrm{B}}(0.025)$ & $0.800^{\mathrm{A}}(0.025)$ & $0.795^{\mathrm{A}}(0.050)$ & $0.791^{\mathrm{A}}(0.032)$ \\
$\mathrm{Heavy}$ metals & & & & \\
$\mathrm{Cu}(\mu \mathrm{g} / \mathrm{g})$ & $5.34^{\mathrm{C}}(0.996)$ & $4.55^{\mathrm{C}}(0.798)$ & $6.86^{\mathrm{B}, \mathrm{C}}(3.16)$ & $10.2^{\mathrm{A}, \mathrm{B}}(1.19)$ \\
$\mathrm{Fe}(\mu \mathrm{g} / \mathrm{g})$ & $73.3(13.7)$ & $57.5(4.30)$ & $61.2(8.54)$ & $43.3(7.16)$ \\
$\mathrm{Mg}(\mu \mathrm{g} / \mathrm{g})$ & $4620^{\mathrm{A}}(150)$ & $3580^{\mathrm{B}}(70)$ & $2520^{\mathrm{C}}(120)$ & $3600^{\mathrm{C}}(90)$ \\
$\mathrm{Mn}(\mu \mathrm{g} / \mathrm{g})$ & $88.4^{\mathrm{B}}(3.15)$ & $116^{\mathrm{A}}(3.53)$ & $111^{\mathrm{A}}(8.42)$ & $111^{\mathrm{A}}(5.92)$ \\
$\mathrm{Ni}(\mu \mathrm{g} / \mathrm{g})$ & $9030^{\mathrm{A}}(236)$ & $7630^{\mathrm{B}}(150)$ & $7500^{\mathrm{B}}(454)$ & $7500^{\mathrm{B}}(343)$ \\
$\mathrm{Zn}(\mu \mathrm{g} / \mathrm{g})$ & $743^{\mathrm{B}}(21.9)$ & $725^{\mathrm{B}}(20.1)$ & $662^{\mathrm{B}}(51.7)$ & $859^{\mathrm{A}}(29.5)$ \\
\hline & & & &
\end{tabular}




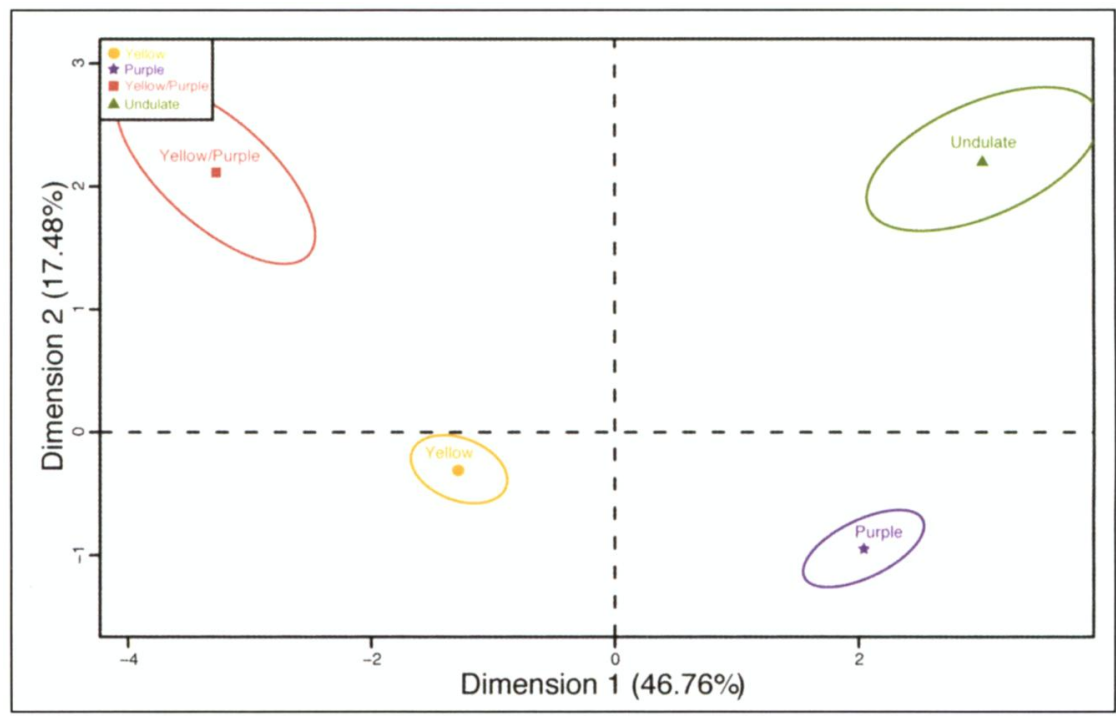

Figure 2a. Principal components analysis (PCA) of $M V \times F T$ (morphological variation [quantitative variable] by floral traits [qualitative category]). Filled symbols signify morph type and represent barycentres (i.e., means) of samples' placement within particular morph categories, with $\mathbf{9 5 \%}$ confidence levels within a category given by ellipses.

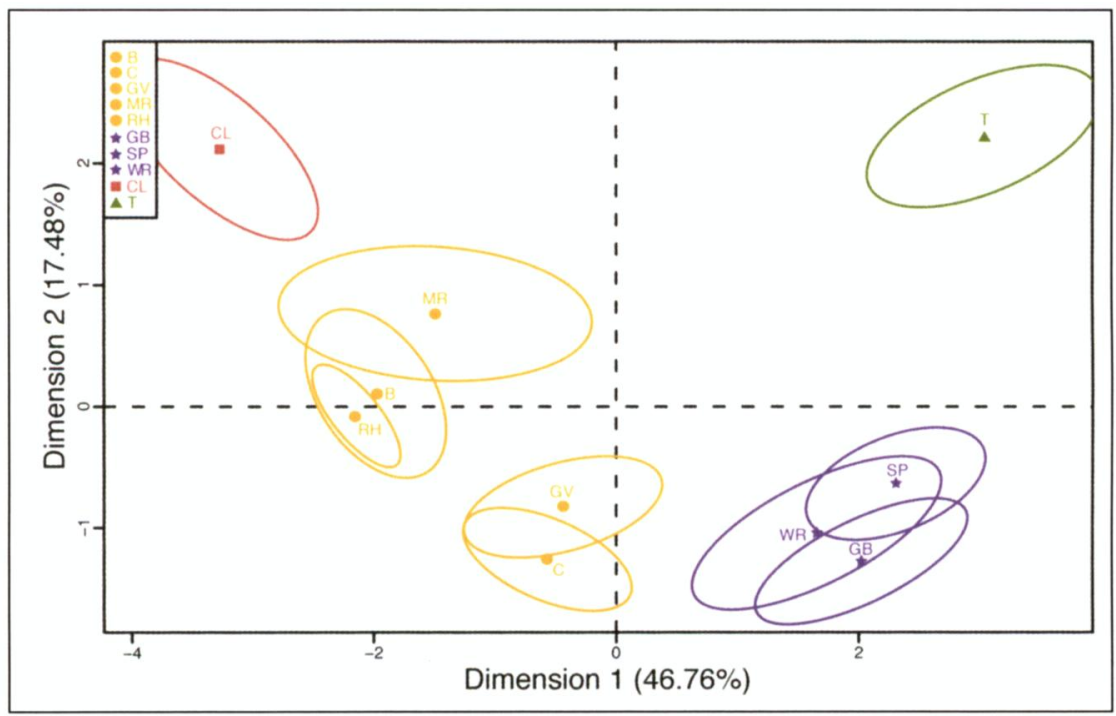

Figure 2b. Principal components analysis (PCA) of $M V \times P O P$ (morphological variation [quantitative variable] by populations [qualitative category]). Filled symbols signify morph type and represent barycentres (i.e., means) of samples' placement within population categories (see Table 1 for population codes), with $95 \%$ confidence levels within a category given by ellipses. Colors in Figure $2 \mathrm{~b}$ reflect floral morph of each population as shown in legend for Figure 2a. 


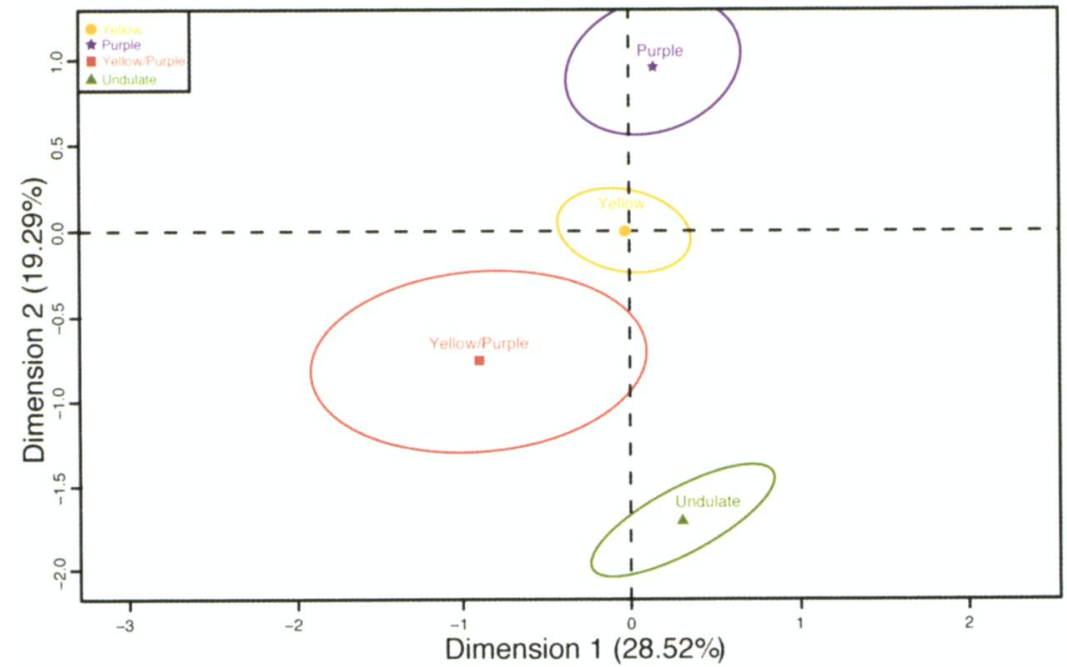

Figure 2c. Principal components analysis (PCA) of $E C \times F T$ (elemental concentration [quantitative variable] by floral traits [qualitative category]). Filled symbols signify morph type and represent barycentres (i.e., means) of samples' placement within particular morph categories, with $95 \%$ confidence levels within a category given by ellipses.

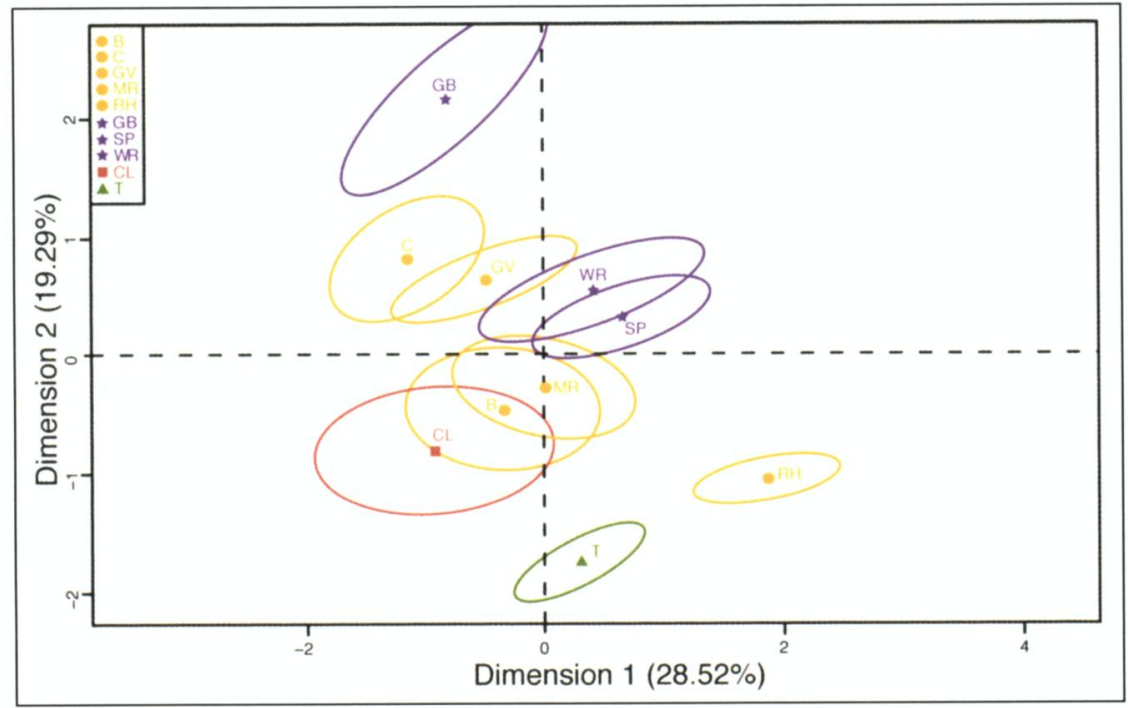

Figure 2d. Principal components analysis (PCA) of $E C \times P O P$ (elemental concentration [quantitative variable] by populations [qualitative category]). Filled symbols signify morph type and represent barycentres (i.e., means) of samples' placement within population categories (see Table 1 for population codes), with $95 \%$ confidence levels within a category given by ellipses. Colors in Figure $2 \mathrm{~d}$ reflect floral morph of each population as shown in legend for Figure 2c. 
across the four morph categories (Fig. 2a; Supplementary Table 1: available online at http://www.eaglehill.us/nena/nena-suppl-files/n16sp5-Boyd-s1, and for BioOne subscribers at http://dx.doi.org/10.1656/N811bb.s1). Elemental concentration also distinguished the morphs, with $\mathrm{Zn}$ and $\mathrm{Ni}$, and $\mathrm{Mg}$ and $\mathrm{Ni}$, being the variables which best described the first and second dimensions, respectively (Supplementary Table 1: available online at http://www.eaglehill.us/nena/nena-suppl-files/n16sp5-Boyd-s1, and for BioOne subscribers at http://dx.doi.org/10.1656/N811bb.s1). Here, the first and second dimensions explained $28.5 \%$ and $19.3 \%$, respectively, of the variability among morphs.

Morphological variation and elemental concentration also distinguished populations within the four morphs, particularly among $\mathrm{Y}$ and $\mathrm{P}$ plants (Figs. 2b,d). For example, two and three distinct clusters of $Y$ populations are apparent based on morphological and phenological traits and elemental concentration, respectively (Fig. $2 b$ ). Likewise, while $\mathrm{P}$ populations formed a tight and overlapping cluster when only morphological variation was considered (Fig. 2b), two groups were discernable based on elemental concentration (Fig. 2d). While the single-population $U$ and $Y / P$ plants tended to segregate from $Y$ and $P$ populations (Figs. 2b,d), the elemental concentration of the County Line (CL) Y/P population overlapped with two Y populations (Marshall Road [MR] and Bagby [B]: Fig. 2d). Interestingly, variation in morphological/phenological traits (Fig. 2b) as well as elemental

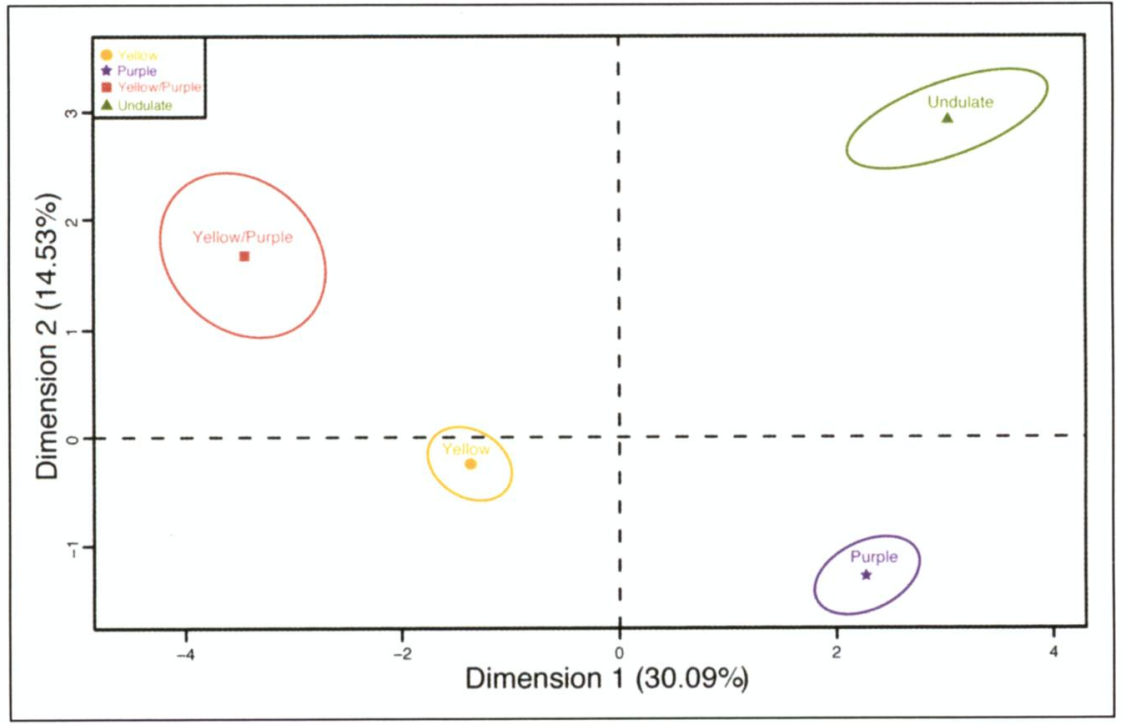

Figure 2e. Principal components analysis (PCA) of $M V+E C \times F T$ (combined morphological variation and elemental concentration [quantitative variable] by floral traits [qualitative category]). Filled symbols signify morph type and represent barycentres (i.e., means) of samples' placement within population categories, with $95 \%$ confidence levels within a category given by ellipses. 
concentration (Fig. 2d) in $\mathrm{Y}$ and $\mathrm{P}$ plants appears to show a geographical arrangement, with populations from similar latitudes (Table 1) arranged in a north to south manner along the second PCA dimension.

Analysis of the combined morphological variation and elemental concentration datasets produced similar patterns to those discussed above. Specifically, the first and second dimensions explained $30.1 \%$ and $14.5 \%$, respectively, of variability among the morphs (Fig. 2e). Here, the morphologi$\mathrm{cal} /$ phenological trait relative sinus width and the elemental concentrations of $\mathrm{Mg}, \mathrm{K}$, and $\mathrm{Ni}$ were the variables that best described the first dimension, with height to first flower and $\mathrm{K}$ and $\mathrm{P}$ concentrations best describing the second dimension (Supplementary Table 1). At the population level, $U$ and Y/P plants were distinct from those of $\mathrm{Y}$ and $\mathrm{P}$, with plants from the latter two morphs subdividing into $2-3$ distinguishable populations or clusters (Fig. $2 \mathrm{f}$ ).

\section{Discussion}

Analysis of morphological and phenological features of the four S. polygaloides morphs showed differences between them in a common garden setting. In general, the $\mathrm{U}$ and $\mathrm{Y} / \mathrm{P}$ morph plants were larger than $\mathrm{Y}$ and $\mathrm{P}$ morph plants, with larger leaves (Table 2). On the other hand, $U$ and $Y / P$ morphs differed greatly from each other in degree of leaf lobing. Leaves of $U$ morph plants had wide sinuses and shallow lobes, whereas Y/P plants had very narrow sinuses

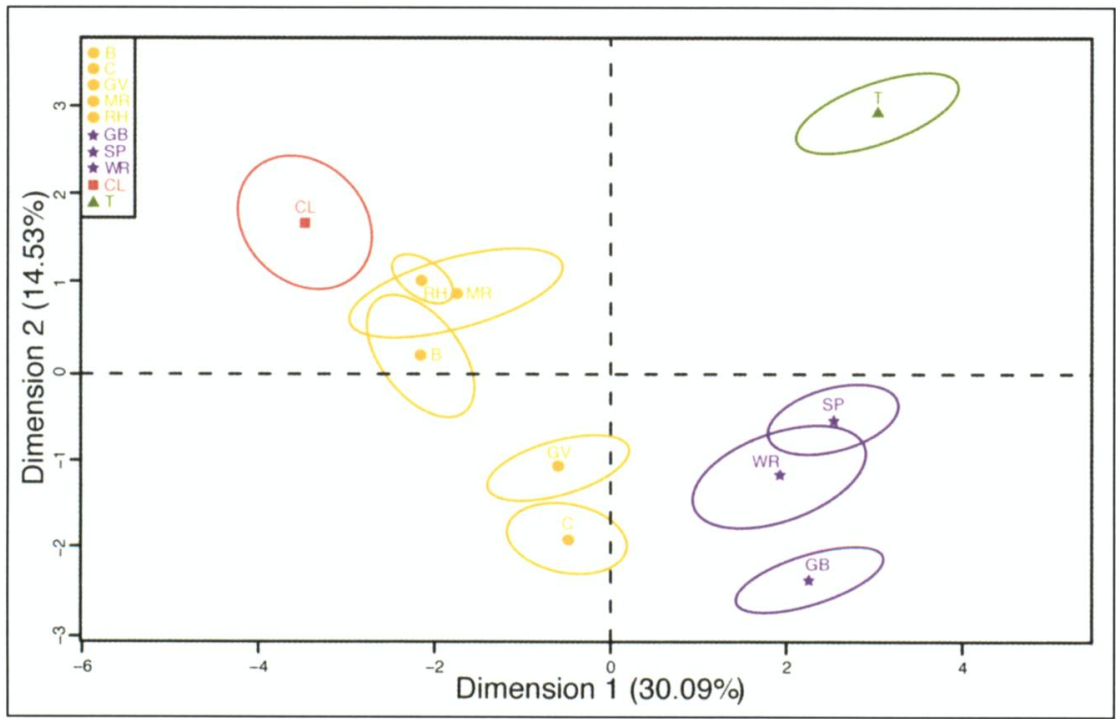

Figure 2f. Principal components analysis (PCA) of $M V+E C \times P O P$ (combined morphological variation and elemental concentration [quantitative variable] by populations [qualitative category]). Filled symbols signify morph type and represent barycentres (i.e., means) of samples' placement within population categories (see Table 1 for population codes), with $95 \%$ confidence levels within a category given by ellipses. Colors in Figure $2 \mathrm{f}$ reflect floral morph of each population as shown in legend for Figure 2e. 
and long narrow lobes. Comparison of $\mathrm{Y}$ and $\mathrm{P}$ morph plants, which were best represented in the dataset due to their wider geographic ranges, showed differences between them in plant height and leaf lobe characteristics (sinus width, lobe width, lobe length, and the ratios measured). We conclude that the four morphs of $S$. polygaloides differ from one another in traits other than the floral ones that we used to initially define these morphs (Wall and Boyd 2006).

Elemental analysis also showed significant variation among the morphs. The $\mathrm{P}$ morph had significantly more $\mathrm{Ni}$ and $\mathrm{Mg}$, and less $\mathrm{P}$ and $\mathrm{Mn}$, than other morphs, while the $\mathrm{U}$ morph had more $\mathrm{Zn}$ and $\mathrm{K}$, and less $\mathrm{Ca}$, than other morphs (Table 3). These differences support the suggestion that these morphs differ physiologically from each other, as shown by their differing responses to the same growth conditions.

The PCAs supported the above results, showing that the morphs were distinct from one another in both morphological/phenological (Fig. 2a) and elemental traits (Fig. 2c). The PCA of the combined morphological/phenological and elemental datasets showed clear separation of the four morphs from one another (Fig. 2e). The PCAs also allowed us to explore variation within the $\mathrm{Y}$ and $\mathrm{P}$ morphs, as multiple populations of those morphs were included in the study. We found Y morph populations separated into two or three clusters along a north-south geographic axis (Figs. 2b,d,f), showing that additional variability occurs within the $\mathrm{Y}$ morph. The $\mathrm{P}$ morph populations showed greater consistency in their morphological/phenological traits and clustered together closely in Fig. $2 b$, but we found marked divergence of the GB population from the other two in elemental concentrations (Fig. 2d). These findings suggest that $\mathrm{Y}$ and $\mathrm{P}$ morphs may be subdivided further upon more detailed study, perhaps reflecting isolation and divergence of these populations on the patchy serpentine habitats of the western Sierra Nevada (Alexander et al. 2007).

Two of the morphs we studied (the U and Y/P morphs) are, to our knowledge, extremely limited in geographic distribution. The Y/P morph's floral color change suggested it was intermediate (perhaps as a hybrid) between the $\mathrm{Y}$ and the $\mathrm{P}$ morphs, yet that was not supported by the morphological and elemental data. For example, plants of the Y/P morph were taller than either the $\mathrm{P}$ or the Y morphs and had the narrowest leaf lobes of all morphs studied. They also were not intermediate between $\mathrm{P}$ and $\mathrm{Y}$ morphs in element concentrations (Table 3). Placement of the Y/P population in the PCAs (Figs. 2b,d,f) also showed it was not intermediate between the $\mathrm{Y}$ and $\mathrm{P}$ populations in $\mathrm{PC}$ space. Thus, our data suggest this morph is not a hybrid between $\mathrm{Y}$ and $\mathrm{P}$ morphs. Genetic sequence data would be very helpful in testing this question.

The other geographically limited morph is the $U$ morph, which is found in the Kings River serpentine locality (Alexander et al. 2007). This serpentine area is separated from the nearest northern serpentine area by about 70 $\mathrm{km}$ (Alexander et al. 2007). The geographic isolation of this serpentine area, which to our knowledge is the southern-most locality of $S$. polygaloides, suggests an opportunity for genetic isolation and thereafter divergence from the 
other (more northern) $S$. polygaloides populations. We found the U morph to be relatively distinctive both morphologically and in elemental composition (Figs. 2b,d,f) relative to the more common Y and P morphs. Again, genetic sequence data may be able to resolve the evolutionary relationship between the relatively isolated $\mathrm{U}$ morph and the other morphs of $S$. polygaloides.

While differences in elemental make-up of these plants could result from genetic differentiation between the morphs, it also may have an ecological function. For example, hyperaccumulated $\mathrm{Ni}$ has been suggested as an elemental plant defense against natural enemies (see review in Boyd 2007). If this is the case, and $\mathrm{Ni}$ level is positively correlated with risk of attack by natural enemies, the $\mathrm{P}$ morph's greater ability to hyperaccumulate $\mathrm{Ni}$ may reflect a greater risk from natural enemies in those populations. It is also possible that the $\mathrm{P}$ morph has a greater Ni uptake ability due to other ecological factors, such as lower available Ni levels in the higher-elevation (Table 1) serpentine soils of $P$ morph populations.

Our experiment showed that these four morphs are different in both morphological traits and elemental composition when grown in a greenhouse common garden. These differences, along with the varying floral traits used to define the morphs, indicate genetic divergence between the populations represented in our study (Linhart and Grant 1996). If breeding barriers genetically isolate these morphs from one another, then these morphs probably should be considered biological species. Unfortunately, we do not yet know if these morphs hybridize under either laboratory or field conditions. Currently, no cases where these morphs are sympatric have been observed, suggesting that biological and/or geographic barriers in the field may prevent natural hybridization. We note that greenhouse-grown $S$. polygaloides does not spontaneously set seed, implying that pollinators are required for sexual reproduction. Thus, the differing floral traits of these morphs may be due to their association with differing pollinators, and this variation in pollinators may result in barriers to hybridization even if sympatry occurs. The relationships of these morphs to each other, and to other Streptanthus taxa, may be clarified by study of chloroplast or nuclear DNA sequences. Initial work by Mayer and Soltis (1994) placed S. polygaloides within the genus as sister to $S$. tortuosus, but that study used a single low-elevation $S$. polygaloides population from El Dorado County (that, based on our current knowledge of the ranges of these morphs, was the yellow morph). Inclusion of other morphs in such studies would be helpful to determine if they should be recognized as separate taxa.

If one or more morphs are recognized as separate taxa, the question of their taxonomic level (varieties? species?) will need to be considered. As we noted in the Introduction, $S$. polygaloides is distinctive enough within the genus Streptanthus that Greene (1904) suggested it be moved to the monotypic genus Microsemia. Reeves et al. (1981), when they discovered $S$. polygaloides was the only Ni hyperaccumulator in the genus (and one of only several Ni hyperaccumulators in continental North America), suggested 
this distinctive biochemical trait supported recognition of Microsemia. As we pointed out above, Mayer and Soltis (1994) suggested S. polygaloides occupies a phylogenetic position within Streptanthus based on chloroplast DNA sequences, so that varietal level recognition would be congruent with their molecular results. In addition, since we report here that all four morphs hyperaccumulate $\mathrm{Ni}$, and no other species of Streptanthus does (Kruckeberg and Reeves 1995, Reeves et al. 1981), the hyperaccumulation trait further suggests a relatively close relationship among the four morphs. This result also suggests future recognition of morphs, if warranted by the additional studies described above, at the varietal rather than species rank.

Our results also have relevance for the applied use of $S$. polygaloides for phytomining of Ni. Phytomining is the use of a hyperaccumulator plant to remove metal from soil so it can be recovered from the biomass (Pilon-Smits and Freeman 2006). Nicks and Chambers (1998) conducted a study with the Y morph (at the Red Hills site, which was one of our sources of Y morph seeds; Table 1) to examine the economic feasibility of using $S$. polygaloides to extract Ni from serpentine soils. Our study showed that $\mathrm{P}$ morph plants contained significantly more Ni than plants of other morphs when grown on soil of the same Ni concentration, indicating that $\mathrm{P}$ morph plants may be a better choice for phytomining. However, we also found that plants of this morph are the smallest (in terms of height to first flower, leaf length, and leaf width; Table 2). If those size data indicate that $P$ morph plants have less biomass than other morphs, then the decreased biomass may counter the positive effect of the greater Ni concentration in $\mathrm{P}$ morph biomass. Certainly, our results do show that there is significant variation among populations of $S$. polygaloides, and this variation may justify actions to protect and conserve those potentially valuable genetic resources (Whiting et al. 2004).

\section{Acknowledgments}

We wish to thank Guest Editor Susan Lambrecht and two anonymous reviewers for suggestions and comments on an earlier version of this manuscript. Portions of this research were accomplished when the first author was Mellon Visiting Scholar at Rancho Santa Ana Botanic Garden, Claremont, CA.

\section{Literature Cited}

Alexander, E.B., R.G. Coleman, T. Keeler-Wolf, and S.P. Harrison. 2007. Serpentine Geoecology of Western North America: Geology, Soils, and Vegetation. Oxford University Press, New York, NY, USA.

Baker, A.J.M., S.P. McGrath, R.D. Reeves, and J.A.C. Smith. 2000. Metal hyperaccumulator plants: A review of the ecology and physiology of a biological resource for phytoremediation of metal-polluted soils. Pp. 85-107, In N. Terry and G.S. Bañuelos (Eds.). Phytoremediation of Contaminated Soil and Water. CRC Press, Boca Raton, FL, USA. 389 pp.

Boyd, R.S. 2007. The defense hypothesis of elemental hyperaccumulation: Status, challenges, and new directions. Plant and Soil 293:153-176.

Brooks, R.R. 1987. Serpentine and its Vegetation: A Multidisciplinary Approach. Dioscorides Press, Portland, OR, USA. 
Brooks, R.R., J. Lee, R.D. Reeves, and T. Jaffré, T. 1977. Detection of nickeliferous rocks by analysis of herbarium specimens of indicator plants. Journal of Geochemical Exploration 7:49-77.

Greene, E.L. 1904. Certain West American cruciferae. Leaflets of Botanical Observation and Criticism 1:81-90.

Harrison, S. and B.D. Inouye. 2002. High $\beta$ diversity in the flora of Californian serpentine "islands." Biodiversity and Conservation 11:1869-1876.

Harrison, S., H.D. Safford, J.B. Grace, J.H. Viers, and K.F. Davies. 2006. Regional and local species richness in an insular environment: Serpentine plants in California. Ecological Monographs 76:41-56.

Kruckeberg, A.R. 1957. Variation in fertility of hybrids between isolated populations of the serpentine species, Streptanthus glandulosus Hook. Evolution $11: 185-211$.

Kruckeberg, A.R. 1958. The taxonomy of the species complex, Strepthanthus glandulosus Hook. Madroño 14:217-248.

Kruckeberg, A.R. 1969. Soil diversity and the distribution of plants with examples from western North America. Madroño 20:137-154.

Kruckeberg, A.R. 1984. California Serpentines: Flora, Vegetation, Geology, Soils, and Management Problems. University of California Press, Berkeley, CA, USA.

Kruckeberg, A.R., and R.D. Reeves. 1995. Nickel accumulation by serpentine species of Streptanthus (Brassicaceae): Field and greenhouse studies. Madroño 42:458-469.

Lê, S., J. Josse, and F. Husson. 2008. FactoMineR: An R package for multivariate analysis. Journal of Statistical Software 25:1-18.

Linhart, Y.B., and M.C. Grant. 1996. Evolutionary significance of local genetic differentiation in plants. Annual Review of Ecology and Systematics 27:237-277.

Mayer, M.S., and P.S. Soltis. 1994. The evolution of serpentine endemics: A chloroplast DNA phylogeny of the Streptanthus glandulosus complex (Cruciferae). Systematic Botany 19:557-574.

Mittermeier, R.A., P.R. Gil, M. Hoffman, J. Pilgrim, T. Brooks, C.G. Mittermeier, J. Lamoreux, and G.A.B. da Fonseca. 2005. Hotspots Revisited: Earth's Biologically Richest and Most Threatened Terrestrial Ecoregions. University of Chicago Press, Chicago, IL, USA.

Nicks, L.J., and M.F. Chambers. 1998. A pioneering study of the potential for phytomining of nickel. Pp. 313-325, In R.R. Brooks (Ed.). Plants that Hyperaccumulate Heavy Metals: Their Role in Phytoremediation, Microbiology, Archaeology, Mineral Exploration, and Phytomining. CAB International, Wallingford, UK.

Pilon-Smits, E.A.H., and J.L. Freeman. 2006. Environmental cleanup using plants: Biotechnological advances and ecological considerations. Frontiers in Ecology and Environment 4:203-210.

R Development Core Team. 2008. R: A language and environment for statistical computing. R Foundation for Statistical Computing, Vienna, Austria. Available online at http://www.R-project.org.

Reeves, R.D. 1992. The hyperaccumulation of nickel by serpentine plants. Pp. 252-277, In A.J.M. Baker, J. Proctor, and R.D. Reeves (Eds.). The Vegetation of Ultramafic (Serpentine) Soils. Intercept, Andover, UK.

Reeves, R.D. and A.J.M. Baker. 2000. Metal-accumulating plants. Pp. 193-229, In I. Raskin and B.D. Ensley (Eds.). Phytoremediation of Toxic Metals: Using Plants to Clean Up the Environment. John Wiley and Sons, New York, NY, USA. 
Reeves, R.D., R.R. Brooks, and R.M. Macfarlane. 1981. Nickel uptake by Californian Streptanthus and Caulanthus with particular reference to the hyperaccumulator S. polygaloides A. Gray (Brassicaceae). American Journal of Botany 68:708-712.

Wall, M.A., and R.S. Boyd. 2006. Melanotrichus boydi (Heteroptera: Miridae) is a specialist on the nickel hyperaccumulator Streptanthus polygaloides (Brassicaceae). Southwestern Naturalist 51:481-489.

Whiting, S.N., R.D. Reeves, D. Richards, M.S. Johnson, J.A. Cooke, F. Malaisse, A. Paton, J.A.C. Smith, J.S. Angle, R.L. Chaney, R. Ginocchio, T. Jaffré, R. Johns, T. McIntyre, G.W. Purves, D.E. Salt, H. Schat, F.J. Zhao, and A.J.M. Baker. 2004. Research priorities for conservation of metallophyte biodiversity and their potential for restoration and site remediation. Restoration Ecology 12:106-116. 